\title{
Double inferior vena cava with L-type crossed fused renal ectopia: A rare case report
}

\author{
Amita ${ }^{1}$, Haq $S^{2}$, Bhatnagar $S^{3}, \operatorname{Garg} S^{4}, \operatorname{Singh} \mathbf{J}^{5}$ \\ ${ }^{1}$ Dr. Amita, Senior Resident, ${ }^{2}$ Dr. Samrin Haq, Junior Resident ${ }^{3}$ Dr. Simmi Bhatnagar, Assistant Professor, \\ ${ }^{4}$ Dr. Sugandha Garg, Junior Resident, ${ }^{5}$ Dr Jasvir Singh, Junior Resident; all authors are affiliated with Departtment of \\ Radiology, GMC, Patiala, Punjab, India.
}

Address for Correspondence: Dr Jasvir Singh, Email: jasvirsingh011789@gmail.com

\begin{abstract}
Duplication of the inferior vena cava (IVC), a rare anomaly reported to occur in $0.2-3 \%$ of the population and is known to be associated with various urogenital tract anomalies such as horseshoe kidneys, crossed fused ectopia and circumaortic renal collar, retroaortic left renal vein and cloacal exstrophy. Inferior vena cava anomalies are rare, Some of such variations have significant clinical, surgical and radiological implications related to other cardiovascular anomalies and in some cases associated with venous thrombosis of lower limbs, particularly in young adults due to the inappropriate venous return increases the pressure, leading to blood stasis in lower extremities and development of varices. Left-sided IVC may cause misdiagnosis with para-aortic lymph node enalargement, and may cause difficulties in the transjugular approach for IVC filter implantation. So, these anomalies should be recognized carefully.
\end{abstract}

Key-words: Double IVC ; L- type crossed fused renal ectopia.

\section{Introduction}

The incidence of duplication of the inferior vena cava (IVC) is about $0.2-3 \%$ [1]. Duplication of the inferior vena cava is a rare vascular anomaly, which needs to be recognized. It is known to associated with renal anomalies like crossed fused ectopia or circumaortic renal collar [2,3]. To the best of our knowledge, very few case reports of co-existence of duplicated IVC with L-shaped crossed fused renal ectopia in the literature.

\section{Case History}

65 years old patient came to Rajindra Hospital Patiala with complaints of abdominal pain and constipation. Patient was referred to radiology department for ultrasonography. On ultrasonography, Left renal fossa is empty and crossed fused renal ectopia was found and a cortical cystic lesion measuring $3.8 \times 3.1 \mathrm{~cm}$ is seen in the lower pole of crossed fused kidney. Also small amount of free fluid was seen in between the gut loops. Double IVC was also found incidentally. CT scan was advised for detailed evaluation which further confirmed the same along with duplicated IVC. Both the ureters are seen on right side however, bilateral ureterovesical junctions are in their respective anatomical location. On CT, contrast filled IVC is seen on both sides of Aorta. Left sided IVC is commencing from left iliac vein and crossing anterior to Aorta in the mesoaortic angle at level of intervertebral disc of D12-L1 vertebrae to join right sided IVC. Both renal veins are seen draining into the respective IVCs. Caecum lies high up in the right hypochondrium. However, Superior mesenteric artery and superior mesenteric vein relationship is maintained. Other CT findings include a tiny calcified focus without any perilesional edema in segment eight of liver suggestive of chronic calcified granuloma. Other

Manuscript received $20^{\text {th }}$ June 2016

Reviewed: $4^{\text {th }}$ July 2016

Author Corrected: $15^{\text {th }}$ July 2016

Accepted for Publication $30^{\text {th }}$ July 2016 
abdominal organs are unremarkable. Few subcentrimetric sized lymph nodes are seen in the mesentery. Patient was referred to surgery department for further evaluation.
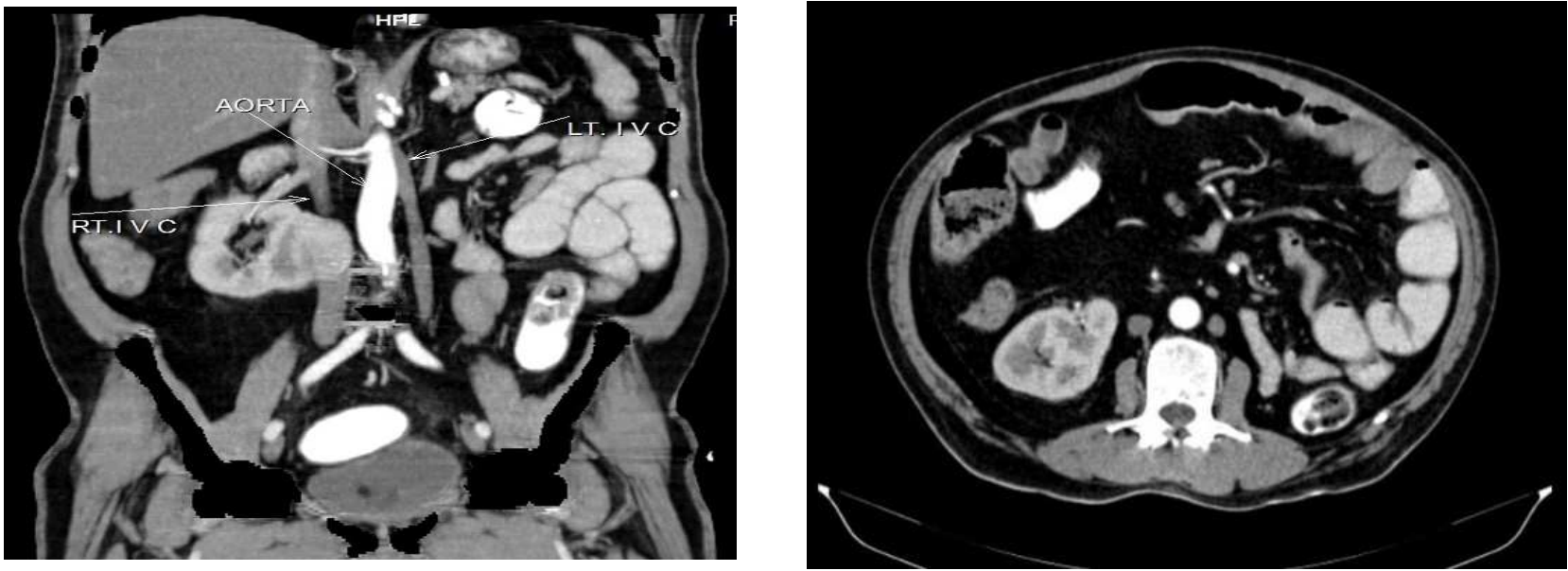

Figure-1:Cornonal CT image showing double IVC Figure-2:Axial CT image showing double IVC in cross section

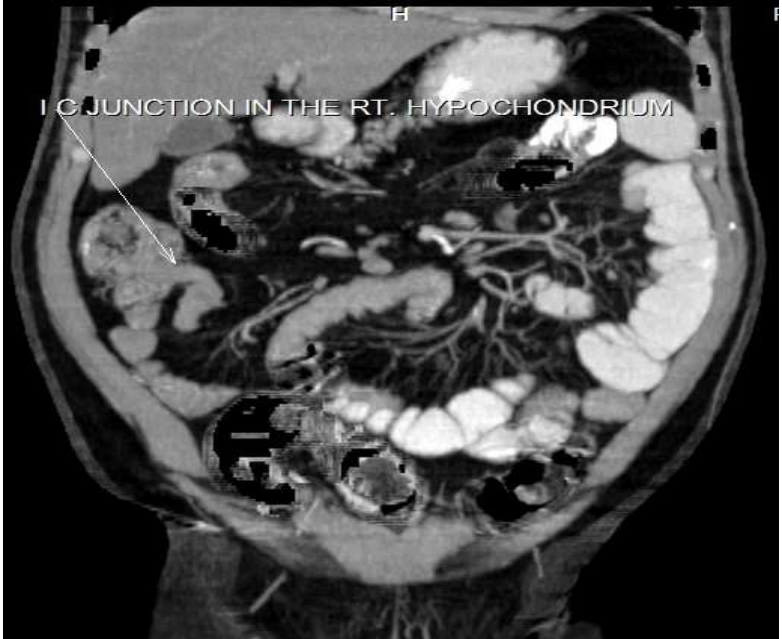

Figure-3: Coronal CT image showing caecum high-up in right hypochondrium

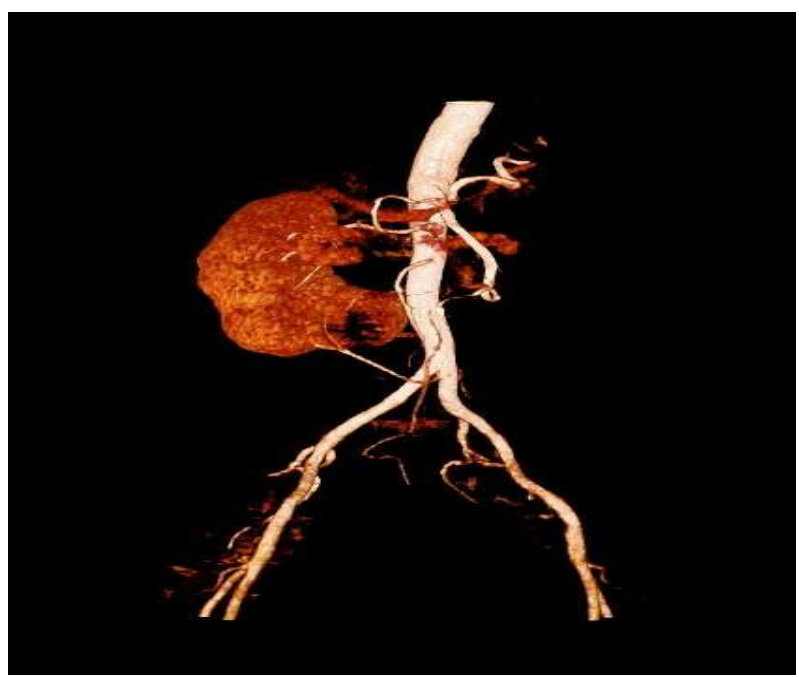

Figure-4:B Axial CT image showing L- shaped crossed fused renal ectopia

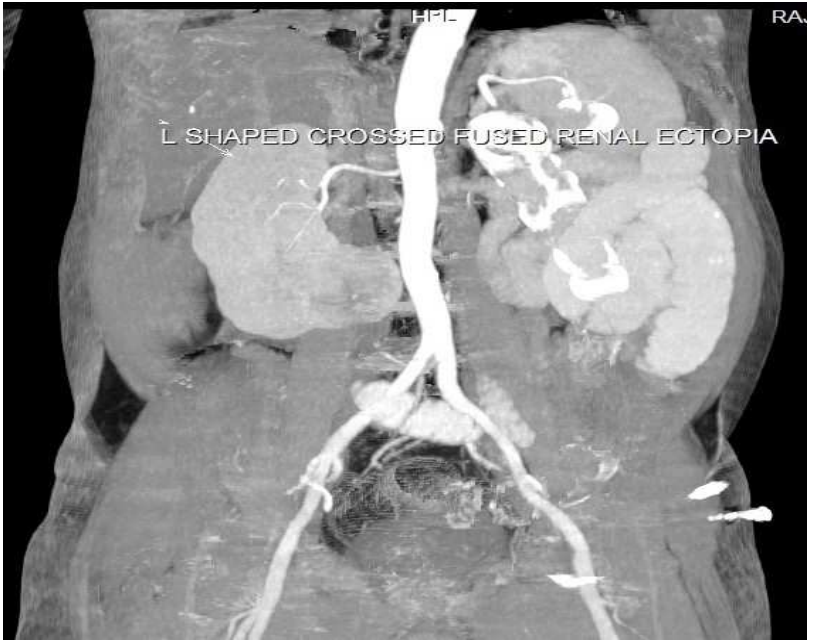

Figure-4:A Axial CT image showing L- shaped crossed fused renal ectopia

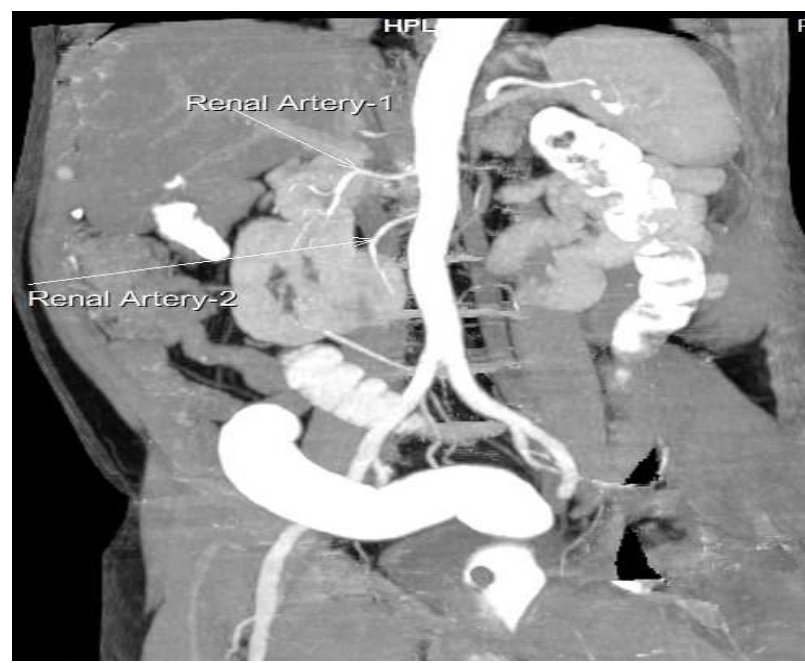

Figure-5:Coronal CT imahes showing two renal arteries 

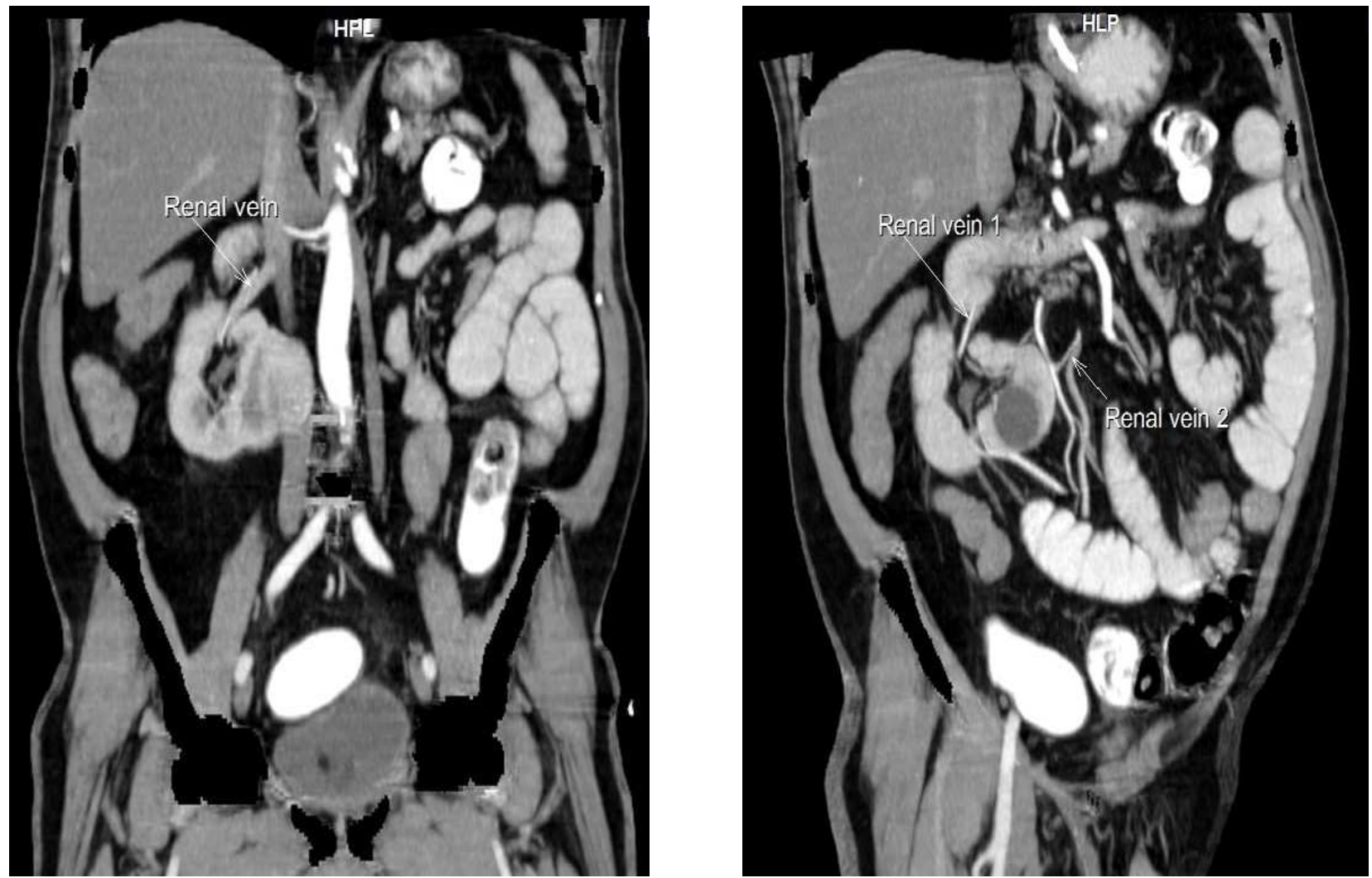

Figure-6: Coronal CT image showing two renal veins

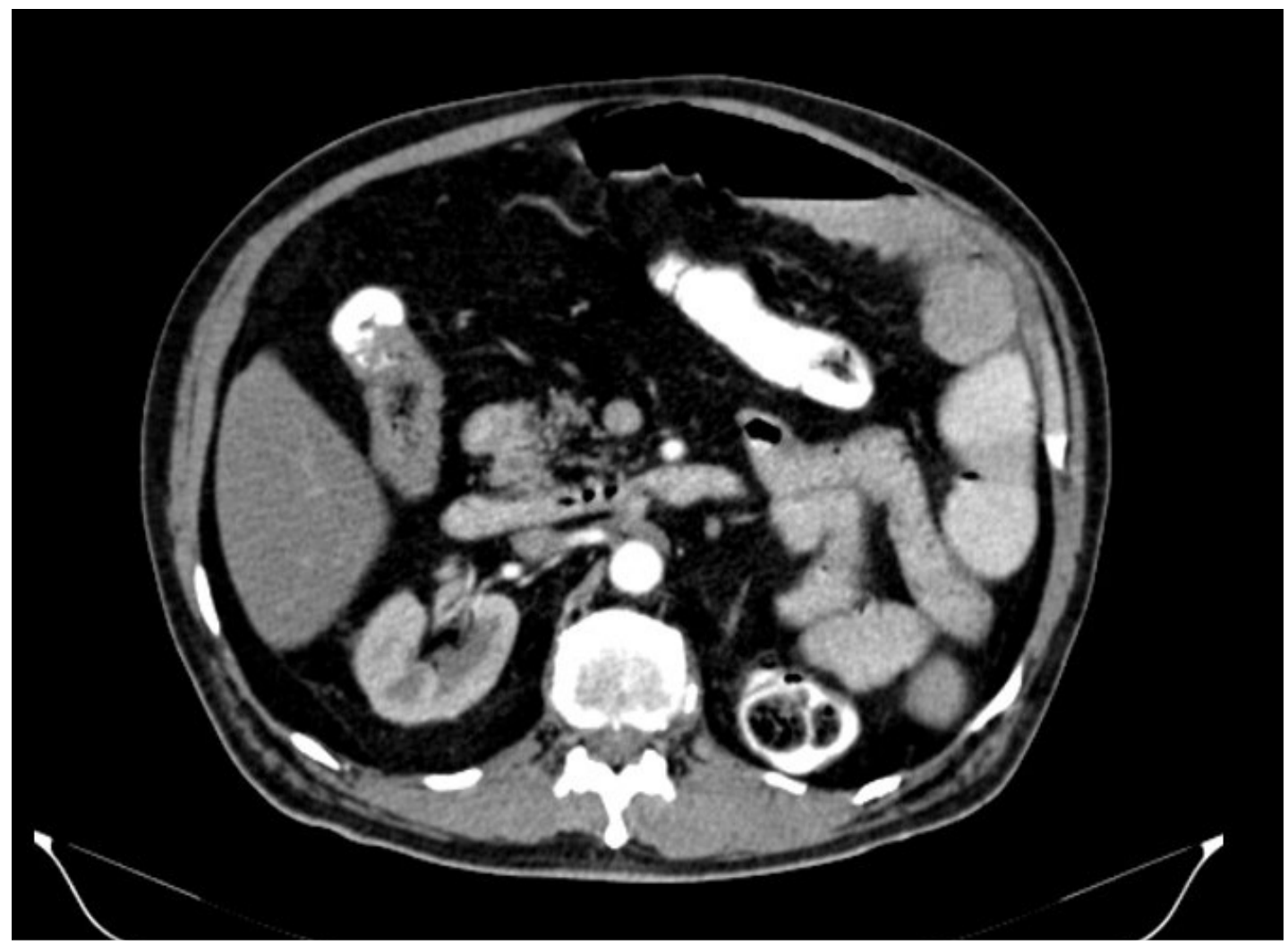

Figure-7: Axial CT image showing normal relationship of Superior mesenteric vein and superior mesenteric artery 

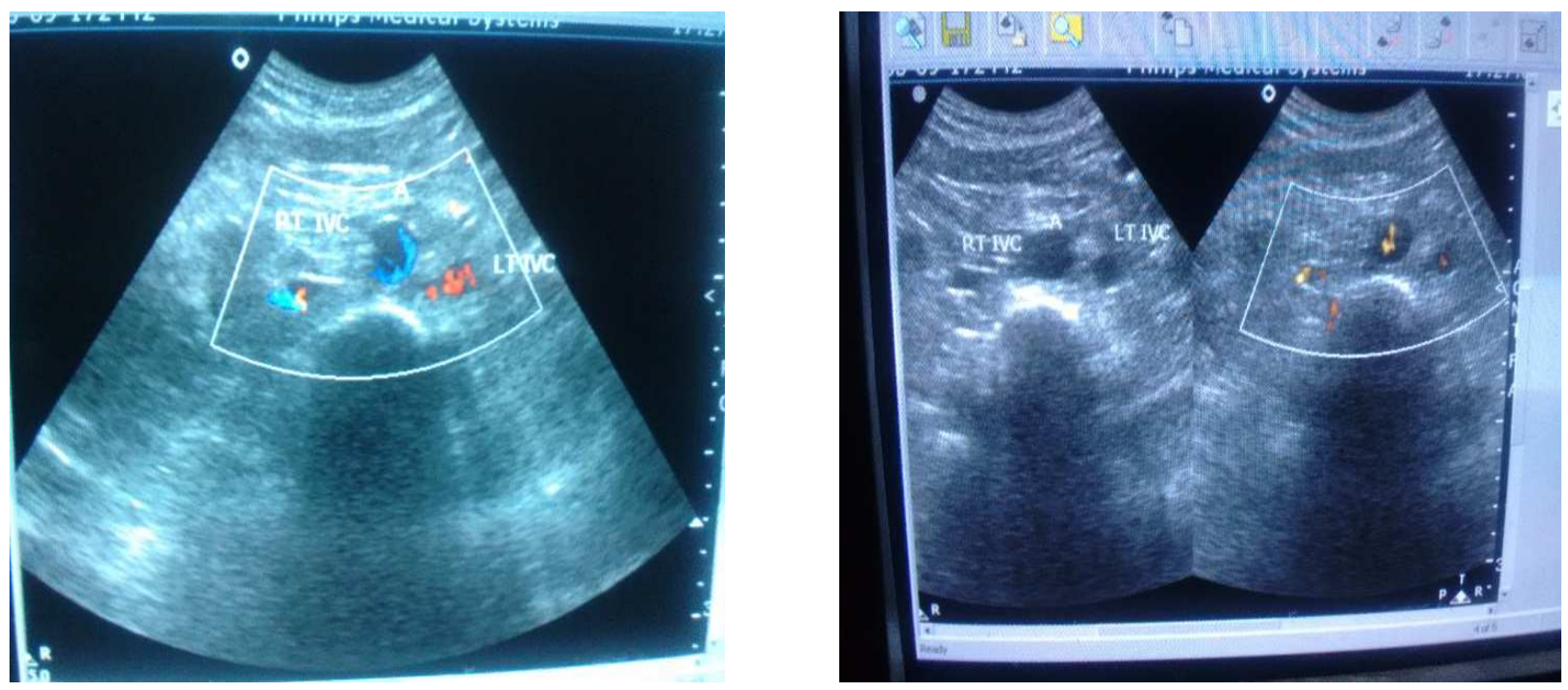

Figure-8 : Ultrasound image showing double IVC

Other investigations- Hematology: Complete blood count, renal function tests, liver function tests, serum calcium levels were within normal limits. Urine routine and microscopy : traces of albumin 1-2 RBCs.

\section{Discussion}

Embryogenesis of the IVC is a complex process. IVC is formed by three paired embryonic veins; the posterior cardinal, the subcardinal and the supracardinal veins. These veins anastomose and then regress (except for the portions that take part in the formation of the IVC) [4]. IVC anomalies result from abnormal regression or abnormal persistence of embryonic veins. A persistent left IVC occurs due to the regression of a right-sided supracardinal vein and the persistence of a left-sided supracardinal vein. It has a reported incidence of 0.2$0.5 \%$ [5]. The left IVC usually crosses the midline anterior to the aorta in the mesoaortic angle (similar to the normal course of a LRV) and joins the right renal vein to form the right IVC. Transposition and duplication of IVC are anomalies of persistence and/or regression of the left and right supracardinal veins,so they are related embryologically [8]. In transposition of the IVC, there is a single inferior vena cava that ascends on the left side of the spine and crosses either anterior or posterior to the aorta at the level of the renal veins to further ascend to the right atrium on the right side of the spine $[6,8,12]$.

In duplication of the Inferior Vena Cava [7,8,12], normal IVC is along the right side of the spine and leftsided IVC ascends up to the level of the renal veins to join the right-side IVC through a vascular connection which is present either anterior or posterior to the aorta at the level of the renal veins. Duplication and transposition of the inferior vena cava may be differentiated by sections caudal to the level of the renal veins. In duplication, the right-side inferior vena cava will be seen as continuous to its bifurcation into the iliac veins, whereas the inferior vena cava will be absent on the right side in transposition of the inferior vena cava.

Crossed fused renal ectopia (CFRE) has autopsy incidence of 1: 2000 to 1: 7500 [9]. It is $2^{\text {nd }}$ most common anomaly after horseshoe kidney. McDonald and McClellan [10] proposed a classification system for CFRE, according to which there are four types of crossed fused ectopia's (i) crossed ectopia with fusion (90\% cases); (ii) Crossed ectopia without fusion' (iii) unilateral crossed ectopia (associated with unilateral renal agenesis) and (iv) bilateral crossed ectopia without fusion (both ureters cross the midline).

Crossed fused renal ectopia is further classified into 6 types [10] These are: type 1) Superior crossed fused ectopia, type 2) Sigmoid or S-shaped kidney, type 3) unilateral lump kidney, type 4) L-shaped kidney, type 5) unilateral disk kidney and type 6) Inferior crossed fused ectopia. Exact mechanism for occurrence of CFRE is not fully understood. However, various theories have been proposed for occurrence of CFRE. According to mechanical theory, abnormally placed umbilical arteries mechanically obstructing cephalad migration; the ureteral theory explains the wandering of 
the ureteral bud to the opposite side, the teratogenic theory, the genetic theory and theory of abnormal rotation of the caudal end of the fetus (in which increased prevalence of this anomaly with scoliosis has been proposed). Mani et al., reported 2 cases with duplication of inferior vena cava is associated with polycystic kidney disease and congenital pelviureteric obstruction [11]. But in our case duplication of IVC associated with crossed fused renal ectopia. The anomalies involving both the inferior vena cava and left renal vein can be divided into four major types: (1) transposition of the inferior vena cava (incidence, $0.2 \%$ $0.5 \%$ ); (2) duplication of the inferior vena cava (incidence, $0.2 \%-3.0 \%$ ); (3) circumaortic left renal vein (incidence, $1.5 \%-8.7 \%$ ); and (4) retroaortic left renal vein (incidence, $1.8 \%-2.4 \%$ ) [12].

\section{Conclusions}

Association of L-shaped crossed fused renal ectopia with double IVC is a rareanomaly. Very few cases have been reported. Moreover, these anomalies have clinical, surgical and radiological implications. So, these should be recognised.

Funding: Nil, Conflict of interest: None initiated, Permission from IRB: Yes

\section{References}

1. Milani C, Constantinou M, Berz D, Butera JN, Colvin GA. Left sided inferior vena cava duplication and venous thromboembolism: case report and review of literature. J Hematol Oncol. 2008 Dec 2;1:24. doi: 10.1186/1756-8722-1-24.

2. Royal SA, Callen PW. CT evaluation of anomalies of the inferior vena cava and left renal vein. AJR Am J Roentgenol. 1979 May;132(5):759-63.

3. Smith TR, Frost A. Anomalous inferior vena cava associated with horseshoe kidneys. Clin Imaging. 1996 Oct-Dec;20(4):276-8.
4. Bass JE, Redwine MD, Kramer LA, Huynh PT, Harris JH Jr. Spectrum of congenital anomalies of the inferior vena cava: cross-sectional imaging findings. Radiographics. 2000 May-Jun;20(3):639-52.

5. Phillips E. Embryology, normal anatomy, and anomalies. In: Ferris EJ, Hipona FA, Kahn PC, Phillips E, Shapiro JH, editors. Venography of the inferior vena cava and its branches. Baltimore Md: Williams and Wilkins; 1969. pp. 1-32.

6. Pillari G, Wind ES, Wiener SL, Baron MG. Left inferior vena cava. AJR Am J Roentgenol. 1978 Feb;130(2):366-7.

7. Berkow AE, Henkin RE. Double inferior vena cava or iliac vein occlusion? A diagnostic problem in radionuclide venograms. AJR Am J Roentgenol. 1978 Mar;130(3):529-31.

8. Chuang VP, Mena CE, Hoskins PA. Congenital anomalies of the inferior vena cava. Review of embryogenesis and presentation of a simplified classification. Br J Radiol. 1974 Apr;47(556):206-13.

9. Bauer SB. Anomalies of the upper urinary tract. In :Walsh PC, Retik AB, Vaughan ED, Wein AJ, editors "Campbell's Urology", 8th. Ed. Philadelphia, W.B.Saunders Co., 2002; p 1898-1902.

10. MCDONALD JH, MCCLELLAN DS. Crossed renal ectopia. Am J Surg. 1957 Jun;93(6):995-1002.

11. Mani N, Venkataramu NK, Singh P, Suri S. Duplication of IVC and associated renal anomalies. Indian Journal of Radiology and Imaging. 2000;10(3):157-58.

12. Brener BJ, Darling RC, Frederick PL, Linton RR. Major venous anomalies complicating abdominal aortic surgery. Arch Surg. 1974 Feb;108(2):159-65.

\section{How to cite this article?}

Amita, Haq S, Bhatnagar S, Garg S, Singh J. Double inferior vena cava with L-type crossed fused renal ectopia: A rare case report. Int J Med Res Rev 2016;4(8):1425-1429.doi:10.17511/ijmrr.2016.i08.23. 